\title{
Numerical Study of Multi-Fuel Jet Inverse Diffusion Flame
}

\author{
Nadjib. Ghiti ${ }^{1, *}$, Abed Alhalim. Bentebbiche ${ }^{1}$, Samir. Hanchi ${ }^{2}$ \\ ${ }^{1}$ Laboratoire de Mécanique Avancée-LMA,USTHB, Elia, Bab-Ezzouar, Alger, Algeria \\ ${ }^{2}$ Laboratoire de Mécanique des Fluides, EMP, Bordj El Bahri, Alger, Algeria \\ *Corresponding author: ghitinadjib@yahoo.fr
}

Received January 03, 2013; Revised May 18, 2013; Accepted May 19, 2013

\begin{abstract}
A numerical simulation was performed to investigate a multi-jet inverse methane diffusion flame. The numerical simulation was established by the commercial CFD code Fluent for an air jet surrounding by four fuel jets. Using a Pre PDF technique to estimate the interaction between the chemistry and turbulent flow. The simulation results show a better data of the flame temperature field characteristics and the $\mathrm{CO}, \mathrm{CO}_{2}, \mathrm{NO} \mathrm{H}_{2} \mathrm{O}, \mathrm{CH}_{4}, \mathrm{O}_{2}$ concentrations. The influence of the velocity of the fuel and air jet on the NO production is appearing very clear.
\end{abstract}

Keywords: methane, turbulent, diffusion flame, fluent, burner

\section{Introduction}

Impinging flame jets have been widely used in industrial and domestic heating applications for their enhanced convective heat transfer rates [1,2]. The thermal performance of a flame impingement system is dependent significantly on four factors: burner style, flame jet properties, impingement surface condition, and configuration between burner nozzle and surface. Extensive literature reviews on impinging flame jets have been carried out by Viskanta [3,4], Baukal and Gebhart [5,6] and Chander and Ray [7]. Comparing to normal diffusion flame (NDF), premixed or partially premixed flames are normally used for impingement heating because of high flame temperature and soot-free flame structure. Structures and heat transfer characteristics of a single or an array of two or three laminar or turbulent premixed flame jet have been studied by several researchers $[8,9]$. A cold central core with low heat flux around the stagnation point is found by several investigators [10,11]. Kataoka et al. [12] and Kataoka [13] found that the maximum heat transfer occurs at the stagnation point when the nozzle-to-plate distance is equivalent to the jet potential core length when combusted methane/ air gases impinge upwards normally on a flat plate. Hargrave et al. [14,15] investigated the flame structure and heat transfer characteristics of a turbulent premixed methane/air flame jet. Van der Meer [16] investigated the heat transfer characteristics of a turbulent natural gas/air impinging flame jet with both experimental and numerical methods. The effects of the nozzle-to-plate angle on the heat transfer characteristics have been investigated by Kremer et al. [17] and Dong et al. [18]. Tuttle et al. $[19,20]$ investigated experimentally both the time-averaged and time-resolved heat transfer characteristics of a single impinging partially premixed methane/air flame jet. An array of two or three impinging premixed flame jets have been investigated by Dong et al. [21,22] and Chander and Ray [23].Malikov et al. [24] studied numerically heat transfer in a rapid heating furnace with a multi-jet combustion chamber. Some researchers found that the IDF is capable of achieving ultra-low levels of NOx to less than $18 \mathrm{ppm}[25,26]$. However, most IDFs studied before are not suitable for impingement heating because of the yellow flame appearances with excess soot emission. The applications, physics of the flow and heat transfer phenomena, available empirical correlations and values they predict, and numerical simulation techniques and results of impinging jet devices for heat transfer are described in [27].

In this paper we investigate numerically using commercial CFD code Fluent an inverse diffusion multijet methane flame in order to characterize the heat transfer and NO, CO produced during the combustion process for different equivalent ration.

\section{Burner Geometry}

The domain is meshed by a grid generator GAMBIT associated with FLUENT, which consists of 56296 nodes. The numerical grids were meshed using tetrahedral elements. No-slip boundary condition was imposed on the walls. The turbulence intensity at fuel inlets and air inlet is set at $10 \%$. Air and methane, as the working fluids, was assumed incompressible, but the properties other than density were treated as temperature-dependent. Modeling of turbulence used the RNG $k-\varepsilon$ model. A converged solution was obtained when the residuals were less than $10^{-6}$ in the energy equation and $10^{-3}$ in the momentum, continuity, and turbulence equations. The interaction between chemistry and turbulence was treated with the Pre PDF model which assume that all the chemical species are depend on the mean mixture fraction and the variance of the mean mixture fraction, only the NO production assumed infinite fast chemistry model Figure 1. 


$$
\begin{aligned}
& \mathrm{d}_{1}=2.4 \mathrm{~mm} \\
& \mathrm{~d}_{2}=6 \mathrm{~mm} \\
& \mathrm{~d}_{3} / 2=7.2 \mathrm{~mm} \\
& \mathrm{~d}_{4}=30 \mathrm{~mm}
\end{aligned}
$$

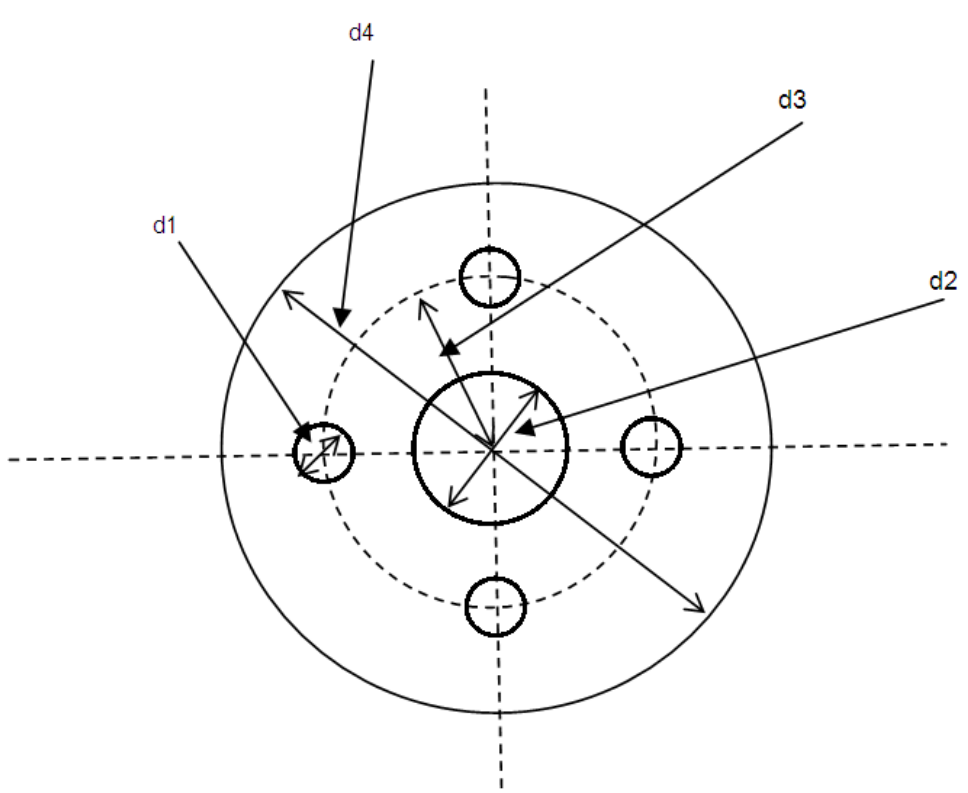

Figure 1. Burner geometry design description

\section{Results and Discussion}

The temperature field Figure 2 characterized by the methane flame from the four methane jets surrounding the air jet. The flame base where fuel entrainment occurs is a low temperature region due to the lack in chemical reactions and there is even a cool core with temperature below $500 \mathrm{~K}$, which corresponds to the potential core of the air jet. As chemical reactions evolve above the flame neck and in the mixing zone, flame temperature gradually increases while the temperature at the center of the flame is still the lowest due to presence of excess air near the flame axis. The mixing process of supplied air and fuel is finally completed in the mixing region before it reaches the main reaction zone which is typically associated with maximum flame temperature [28].

In this case, the behavior of the jet is very complex and different from a jet issued from single jet flame.
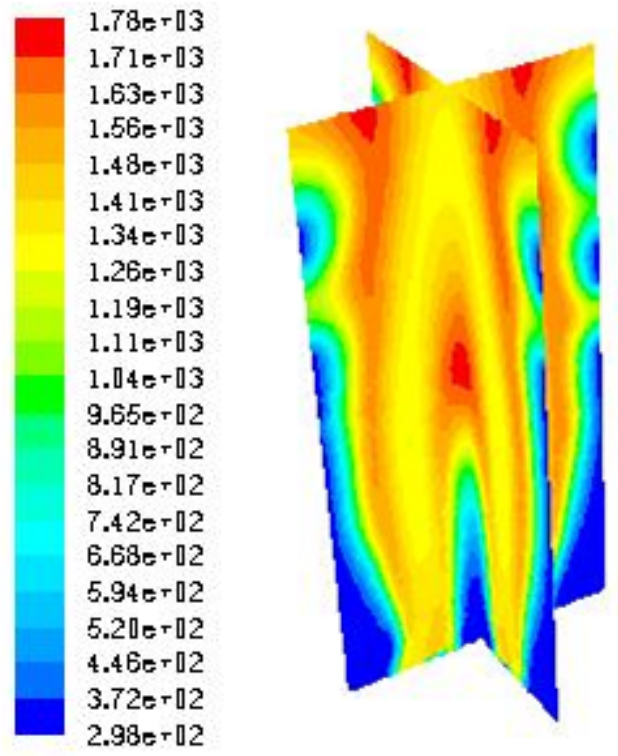

Figure 2. three dimensions contours of temperature for an inverse diffusion methane flame $(\mathrm{K})$

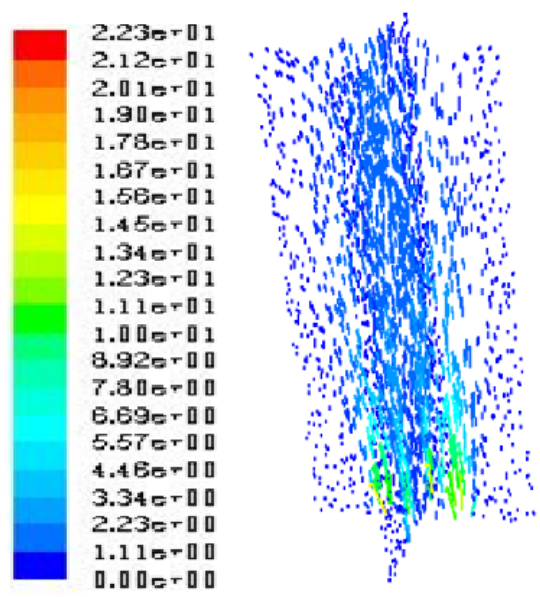

Figure 3. Velocity vectors colored by velocity magnitude $(\mathrm{m} / \mathrm{s})$, air inlet $=2.5 \mathrm{~m} / \mathrm{s}$, fuel inlet $=5 \mathrm{~m} / \mathrm{s}$

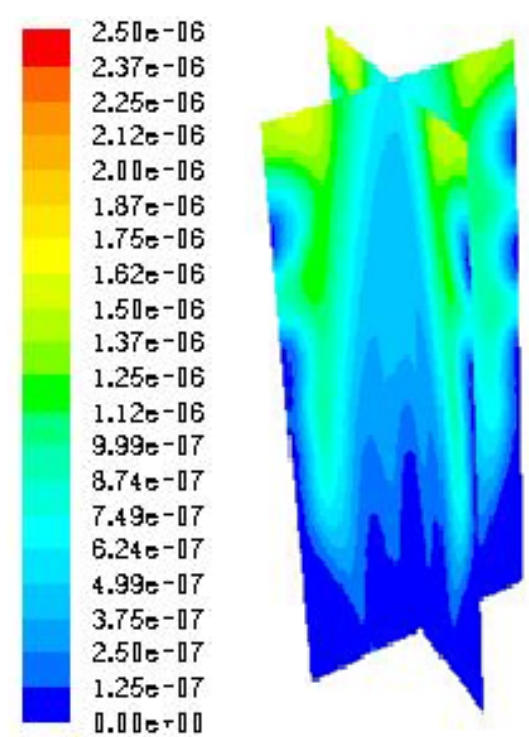



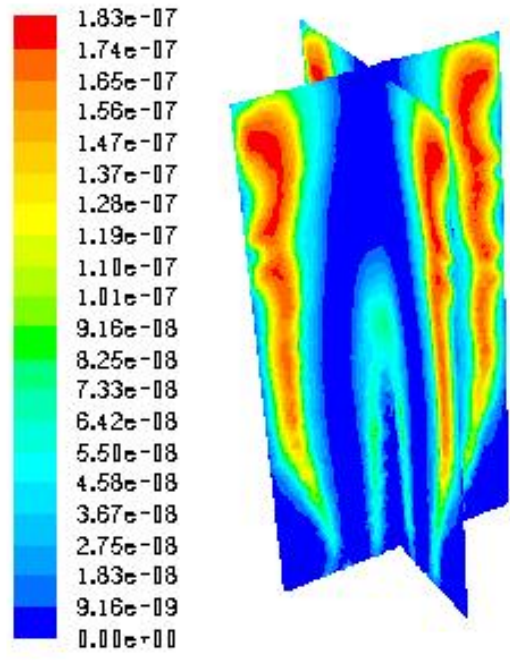

Figure 5. three dimensions contour of mass fraction of pollutant $\mathrm{N}_{2} \mathrm{O}$

The complex geometry of the burner presented in this study lead to a particular flow field of species propagation. The distribution of the velocity and the turbulent intensity is of crescent shape at the exit of the nozzles, with high levels of turbulence, and these values decrease rapidly to low levels after the injection and increase after when the combustion arise.

The requirement to significantly reduce NOx while maintaining combustor performance is one of the main drivers for industrial and domestic burners research. This paper reports on the results of a numerical investigation on the effects of using multi fuel jets surrounding an air jet on NOx emissions in an inverse diffusion flame. The methane flame is computed using the fluent software. Results indicate that, with regard to their NOx characteristics, the diffusion flame can be emitted different types of NO fuel NO and prompt NO and reburn $\mathrm{NO}$ and thermal NO, it depend to the flame temperature and fuel air mixing. It was observed that the prompt NO formation rate in the inverse diffusion flame is significantly higher than the thermal NO and fuel NO.
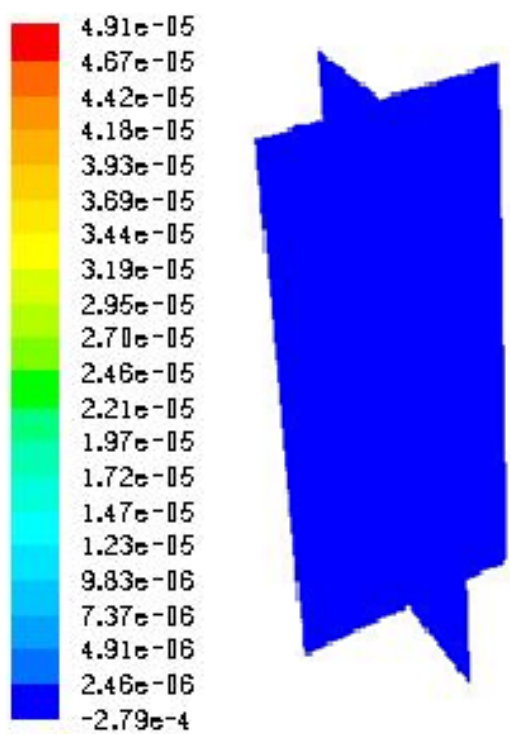

Figure 7. three dimensions contours of rate of prompt $\mathrm{NO}\left(\mathrm{Kgmol} / \mathrm{m}^{3} \mathrm{~s}\right)$

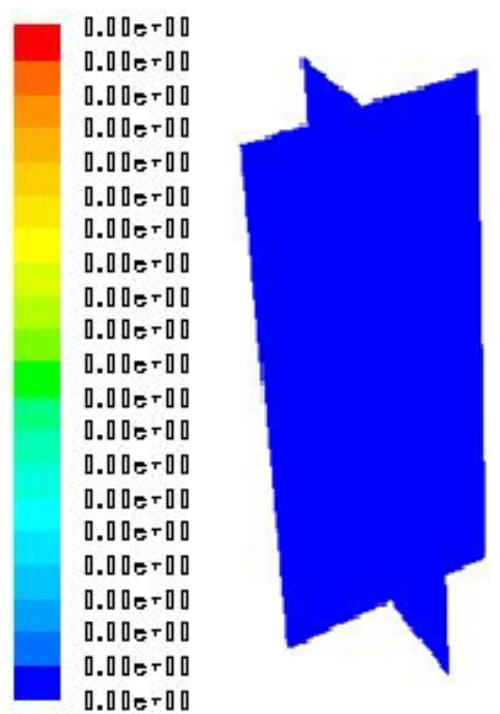

Figure 8. three dimensions contours of rate of fuel NO (Kgmol/m3s)

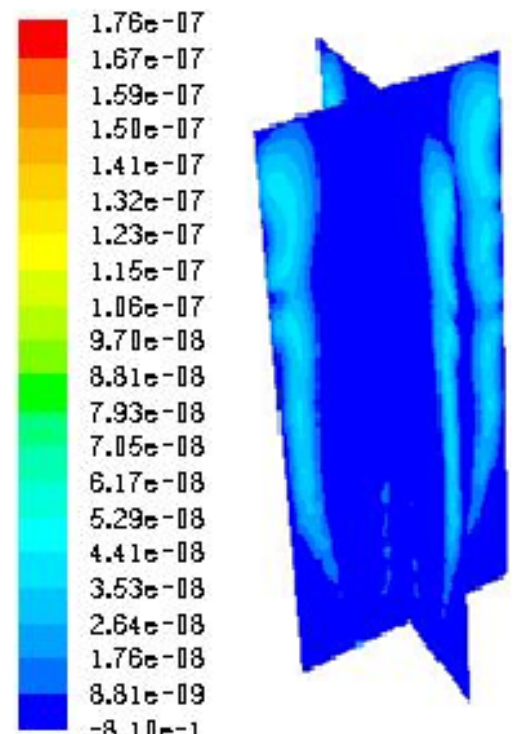

Figure 9. three dimensions contours of rate of $\mathrm{N}_{2} \mathrm{O}$ path $\mathrm{NO}\left(\mathrm{Kgmol} / \mathrm{m}^{3} \mathrm{~s}\right)$
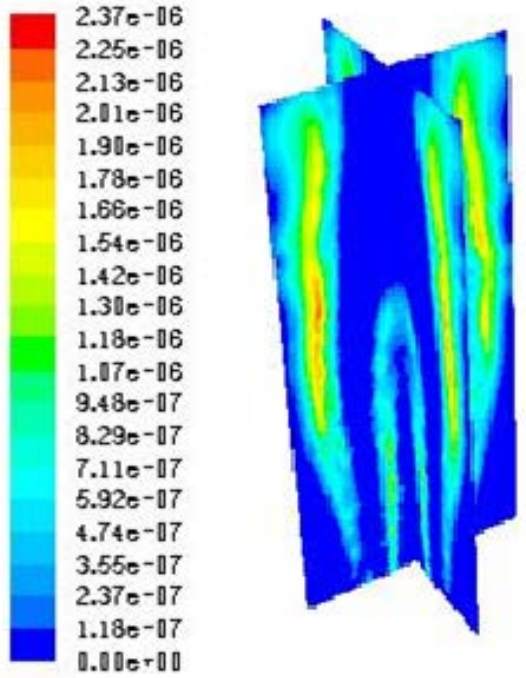
列 


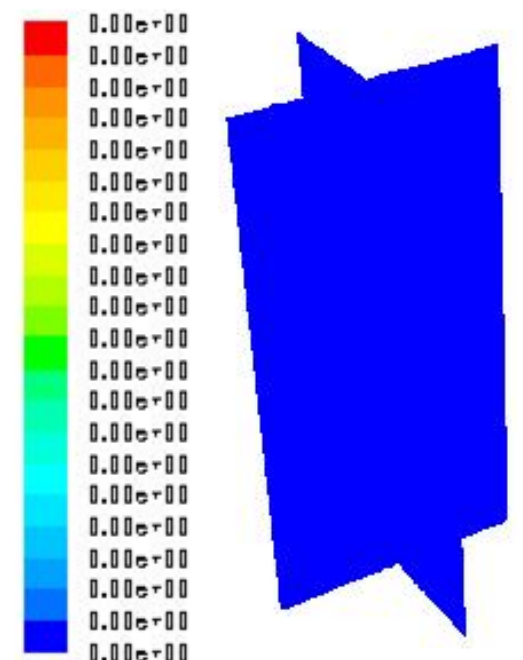

Figure 10. three dimensions contours of rate of reburn $\mathrm{NO}\left(\mathrm{Kgmol} / \mathrm{m}^{3} \mathrm{~s}\right)$

Figure 2 presents the temperature contours of the flame, while Figure 11, Figure 12 and Figure 13 shows the contours of the mole fractions of some species $\mathrm{CH}_{4}, \mathrm{CO}_{2}$, $\mathrm{CO}$. The global flame structure for the methane fuel is influenced by the form of the burners in the sense that the flame contains two distinct reaction zones, namely the first reaction zone near the burners inlet and in the middle reaction zone on the core of the flame reaction mixing with air. The first reaction zone is characterized by the fuel-rich oxidation chemistry that involves the pyrolysis/consumption of fuel, the production of "intermediate fuel" species $\left(\mathrm{C}_{2} \mathrm{H}_{2}, \mathrm{CO}\right.$, and $\left.\mathrm{H}_{2}\right)$, and to a lesser extent production of $\mathrm{CO}_{2}$ and $\mathrm{H}_{2} \mathrm{O}$. The intermediate fuel species are transported to the nonpremixed reaction zone, where they are oxidized to form $\mathrm{CO}_{2}$ and $\mathrm{H}_{2} \mathrm{O}$. Thus, the nonpremixed zone is characterized by the oxidation of these intermediate fuel species.

Due to the differences in ignition characteristics, which are related to the fuel-rich low temperature oxidation chemistry, the premixed reaction zone in methane flame is located farther downstream (from the fuel nozzle).the $\mathrm{OH}$ chemical species shown in Figure 15 gave the flame structure.

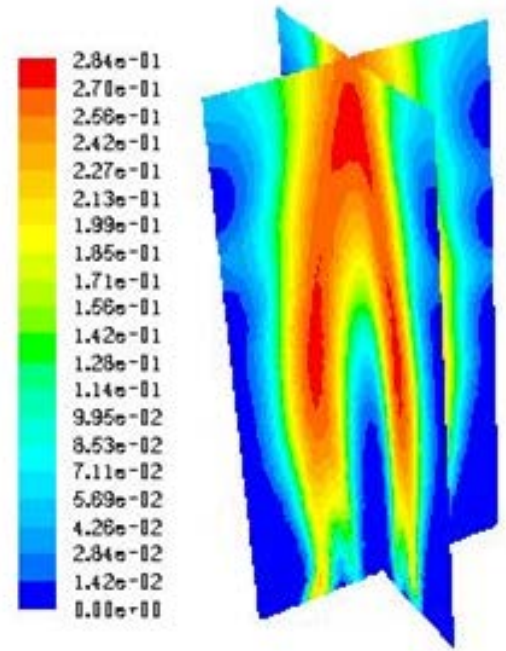

Figure 11. three dimensions contours of mass fraction of CO

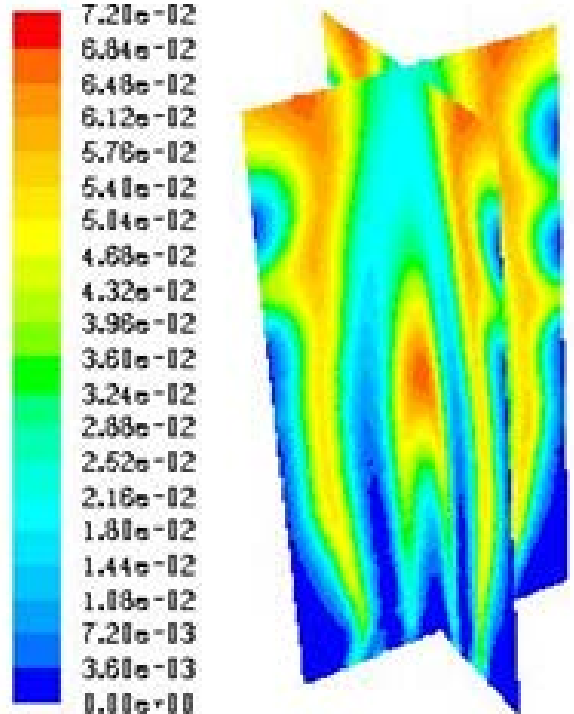

Figure 12. three dimensions contours of mass fraction of $\mathrm{CO}_{2}$
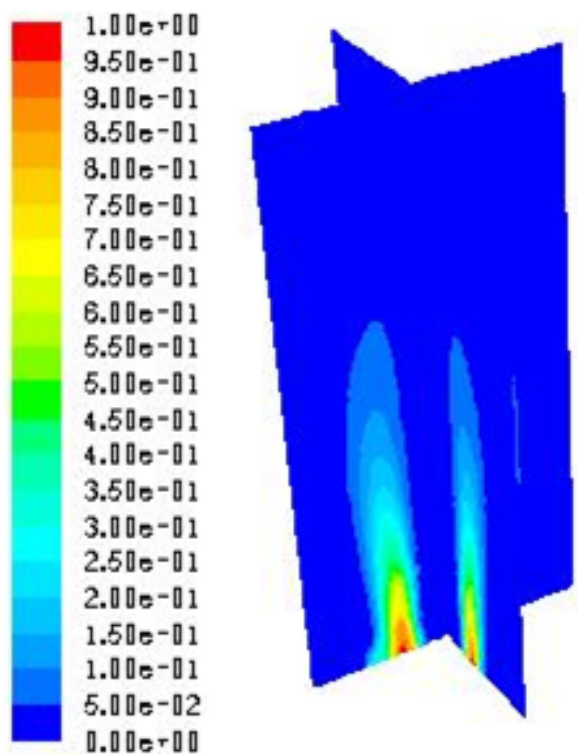

Figure 13. three dimensions contours of mass fraction of $\mathrm{CH}_{4}$
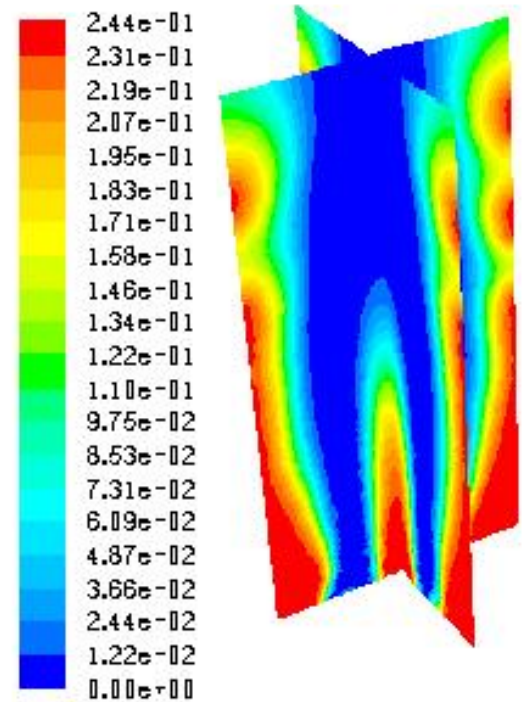

Figure 14. three dimensions contours of mass fraction of $\mathrm{O}_{2}$ 


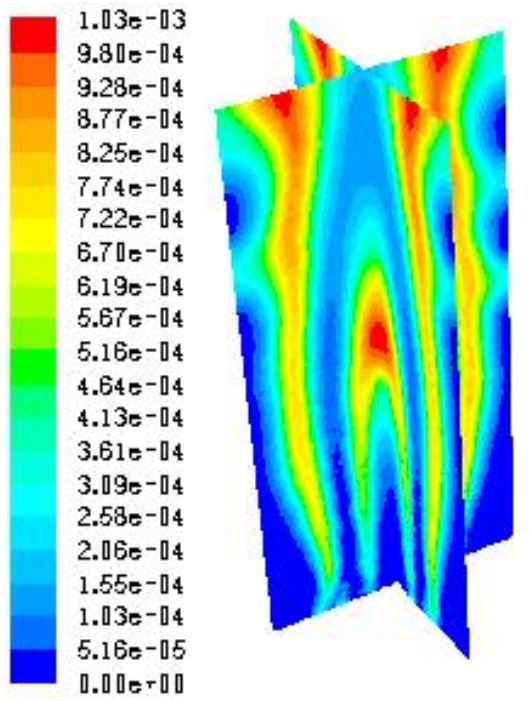

Figure 15. three dimensions contours of mass fraction of $\mathrm{OH}$

In the methane flame, Figure 6, Figure 7, Figure 8 and Figure 10 most of the NO is produced in the nonpremixed zone. However, while most of the NO is produced through the prompt mechanism in the inverse diffusion flame, it is produced mainly through the thermal mechanism in methane diffusion jet flame. This represents an important difference with regard to the NOx characteristics of the inverse diffusion flame and a jet diffusion flame. And in the inverse diffusion flame we observe a high production of $\mathrm{N}_{2} \mathrm{O}$ in the reaction zone Figure 5.

The higher prompt NO in methane flame is due to the significantly larger amount of acetylene transported to the nonpremixed inverse flame, while the higher thermal NO is due to the higher temperature and higher concentrations of $\mathrm{O}$ and $\mathrm{OH}$ radicals in the nonpremixed flame.

Figure 15 the mass fraction $\mathrm{OH}$ describe the shape and form of the inverse diffusion flame this type of flame has conical shape and cold central core surrounding by a reaction zone this due to the geometrical form of the burner.

\section{Conclusions}

The flow pattern, flame structure and pollutants emission characteristics of an inverse diffusion flame jet have been investigated numerically to explore the feasibility for impingement heating. The following conclusions can be drawn from this investigation:

1. The interference between air and fuel jets complicates the flow pattern and determines the flame structure. It is found that the flame shape and structure are mainly dependent on the air jet velocity and the ratio of the air and fuel velocities. It is found that it is this type of IDF that combines the advantage of both diffusion flame and premixed flame, with no possibility of flashback, high flame temperature and acceptable pollutants emission level.

2. The thermal structure of the IDF can be divided into four characteristic zones, i.e., the base flame zone, which is cool and lack in chemical reaction, the mixing zone, which includes the flame neck where the fuel/air mixing is completed, the combustion zone, which refers to the inner cone, and the post-flame zone. The post-flame zone is characterized by chemical reaction in the early stage and air dilution in the latter. The surrounding fuel jets impinge on the central air jet when the velocity difference is large enough. The high pressure around the stagnation point results in the formation of a recirculation zone near the flame neck, which stabilizes the premixed flame torch.

\section{References}

[1] C.J. Hoogendoorn, Cz.O. Popiel, Th.H. van der Meer, Turbulent heat transfer on a plane surface in impingement round premixed plate jets, Int. Heat Transfer Conf. (1978) 107-112.

[2] J.E. Anderson, E.F. Stresino, Heat transfer from flames impinging on flat and cylindrical surfaces, J. Heat Transfer 85 (1963) 49-54.

[3] R. Viskanta, Heat transfer to impinging isothermal gas and flame jets, Exp. Thermal Fluid Sci. 6 (1993) 111-134.

[4] R. Viskanta, Convective and radiative flame jet impingement heat transfer, The Ninth International Symposium on Transport Phenomena in Thermal-Fluids Engineering (1996) 46-60.

[5] C.E. Baukal, B. Gebhart, A review of flame impingement heat transfer studies - Part 1: Experimental conditions, Combust. Sci. Technol. 104 (1995) 339-357.

[6] C.E. Baukal Jr., B. Gebhart, A review of empirical flame impingement heat transfer correlations, Int. J. Heat Fluid Flow 17 (1996) 386-396.

[7] S. Chander, A. Ray, Flame impingement heat transfer: a review, Energy Convers. Manage. 46 (18-19) (2005) 2803-2837.

[8] J.K. Kilham, M.R.I. Purvis, Heat transfer from hydrocarbonoxygen flames, Combust. Flame 16 (1971) 47-54.

[9] T.H. van der Meer, Stagnation point heat transfer from turbulent low Reynolds number jets and flame jets, Exp. Thermal Fluid Sci. 4 (1991) 115-126.

[10] A. Milson, N.A. Chigier, Studies of methane and methane-air flames impinging on a cold plate, Combust. Flame 21 (1973) 295305.

[11] L.L. Dong, C.S. Cheung, C.W. Leung, Heat transfer from an impinging premixed butane/air slot flame jet, Int. J. Heat Mass Transfer 45 (5) (2002) 979-992.

[12] K. Kataoka, H. Shundoh, H. Matsuo, Convective heat transfer between a flat plate and a jet of hot gas impinging on it, Drying 84 (1984) 218-227.

[13] K. Kataoka, Optimal nozzle-to-plate spacing for convective heat transfer in nonisothermal, variable-density impinging jets, Drying Technol. 3 (2) (1985) 235-254.

[14] G.K. Hargrave, M. Fairweather, J.K. Kilham, Forced convective heat transfer from premixed flames-Part 1: Flame structure, Int. J. Heat Fluid Flow 8 (1) (1987) 55-63.

[15] G.K. Hargrave, M. Fairweather, J.K. Kilham, Forced convective heat transfer from premixed flames-Part 1: Impingement heat transfer, Int. J. Heat Fluid Flow 8 (2) (1987) 132-138.

[16] Theo van der Meer, Heat transfer from impinging flame jets, Ph.D. Thesis, 1987, the Delft University, Netherland.

[17] H. Kremer, E. Buhr, R. Haupt, Heat Transfer from Turbulent FreeJet Flames to Plate surfaces (1973) 463-472.

[18] L.L. Dong, C.W. Leung, C.S. Cheung, Heat transfer characteristics of premixed butane/air flame jet impinging on an inclined flat surface, Heat Mass Transfer 39 (2002) 19-26.

[19] S.G. Tuttle, B.W. Webb, M.Q. Mcquay, Convective heat transfer from a partially premixed impinging flame jet. Part 1: Timeaveraged results, Int. J. Heat Mass Transfer 48 (7) (2005) 2361251.

[20] S.G. Tuttle, B.W. Webb, M.Q. Mcquay, Convective heat transfer from a partially premixed impinging flame jet. Part 2: Timeresolved results, Int. J. Heat Mass Transfer 48 (7) (2005) 12521266.

[21] L.L. Dong, C.W. Leung, C.S. Cheung, Heat transfer and wall pressure characteristics of a twin premixed butane/air flame jets, Int. J. Heat Mass Transfer 47 (3) (2004) 489-500.

[22] L.L. Dong, C.W. Leung, C.S. Cheung, Heat transfer of a row of butane/air flame jets impinging on a flat plate, Int. J. Heat Mass Transfer 46 (2003) 113-125.

[23] S. Chander, A. Ray, Heat transfer characteristics of three interacting methane/air flame jets impinging on a flat surface, Int. J. Heat Mass Transfer 50 (3-4) (2007) 640-653. 
[24] G.K. Malikov, D.L. Lobanov, Y.K. Malikov, V.G. Lisienko, R. Viskanta, A.G. Fedorov, Experimental and numerical study of heat transfer in a flame jet impingement system, J. Inst. Energy 72 (1999) 2-9.

[25] W.P. Partridge, N.M. Laurendeau, Nitric oxide formation by inverse diffusion flames in staged-air burners, Fuel 74 (10) (1995) 1424-1430.

[26] B. Fleck, Experimental and Numerical Investigation of the Novel Low-NOx Industrial Burner, Ph.D. Thesis, Queen’s University, 1998.
[27] N. Zuckerman and N. Lior "Jet Impingement Heat Transfer: Physics, Correlations, and Numerical Modeling” Advances In Heat Transfer Vol. 39

[28] Zhen HS, Choy YS, Leung CW, Cheung CS. Effect of nozzle length on the flame and emission behaviors of multi-fuel-jet inverse diffusion flame burner. Appl. Energy 2011; 88:2917-24. 